\title{
Vascular Injuries in Laparoscopic Cholecystectomy: An Underestimated Problem
}

\author{
George Tzovaras $^{\mathrm{a}}$ Christos Dervenis $^{\mathrm{b}}$ \\ a Department of Surgery, University of Thessaly Medical School, Larissa, and b ${ }^{\mathrm{b}}$ First Department of Surgery, \\ Agia Olga Hospital, Athens, Greece
}

\section{Key Words}

Laparoscopic cholecystectomy $\cdot$ Biliary injury $\cdot$ Vascular injury $\cdot$ Reconstruction

\begin{abstract}
Background: Bile duct injury is a severe complication of laparoscopic cholecystectomy and many reports focus on this topic, especially regarding the long-term success of repair of these injuries. There is some concern, however, as to whether concomitant vascular injuries can jeopardize reconstruction of a bile duct injury following laparoscopic cholecystectomy. Methods: A review of the current literature on the clinical significance and management of a concomitant vascular injury to the outcome of reconstruction of bile duct injuries following laparoscopic cholecystectomy. Relevant articles were extracted through PubMed, with secondary references obtained from key articles. Results: Although the relevant literature is generally poor, there is a trend of appearance of relatively large series on the topic over the last five years, as opposed to case reports or small series during the previous decade. Conclusion: The disruption of the hepatic arterial flow during laparoscopic cholecystectomy is usually well tolerated in an otherwise healthy patient. There is strong evidence that concomitant vascular injuries do not have any impact on mortality after biliary reconstruction. There is also evidence that does increase overall morbidity,
\end{abstract}

but when it comes specifically to long-term anastomotic stricture formation, there is no strong evidence to support a negative impact of a concomitant vascular injury; this is especially true for centers/surgeons with HPB interest.

Copyright $\odot 2006$ S. Karger AG, Basel

\section{Introduction}

Vascular injuries during laparoscopic cholecystecomy mainly occur during trocar insertion or during dissection of the Calot's triangle structures $[1,2]$. The first includes either abdominal wall vessels or major intra-abdominal vascular structures, e.g. aorta, portal vein; this review article will focus on the latter. The true incidence of this kind of vascular injury during cholecystectomy is unknown. Although the literature is rich in reports on bile duct injuries, especially after the introduction of laparoscopic cholecystectomy, reports on coexisting vascular injuries are rare [3]. Furthermore, the clinical relevance and impact of vascular injuries on the functional results of biliary reconstruction is unclear.

It has been alleged that the incidence of bile duct injury has been somewhat increased in laparoscopic era [4, 5]. Furthermore, bile duct injuries during laparoscopic cholecystectomy are located more proximal, where typically the right hepatic artery crosses behind the common

\section{KARGER \\ Fax +41613061234 E-Mail karger@karger.ch} www.karger.com
(C) 2006 S. Karger AG, Basel

$0253-4886 / 06 / 0236-0370 \$ 23.50 / 0$

Accessible online at:

www.karger.com/dsu
George Tzovaras, MD

Assist. Professor of Surgery

19 Agorogianni A. Street

Larissa 41335 (Greece)

Tel. +30 2410682 730, Fax +30 2410611 097, E-Mail gtzovaras@hotmail.com 
hepatic duct $[3,4]$. It is possible then that vascular injuries have also been increased with laparoscopy. This is in fact reflected in the recent literature, with relevant reports evolving from case reports and small retrospective series [6-11] to larger and prospective ones [3, 12-16]. The aim of this review article is to address the issue of concomitant vascular injuries with emphasis to its clinical relevance and impact on mortality and morbidity, with special attention to biliary complications.

\section{Incidence}

The true incidence of vascular injuries during cholecystectomy is uncertain, as most reports include highly selected population in the context of bile duct injury, with patients being tertiary referrals and most often treated suboptimally at the first place. In addition, in most centers routine angiography has not been used and the methods applied for diagnosis of concomitant vascular injuries vary among different centers. In an autopsy study [17], the incidence of right hepatic artery injury after open cholecystectomy has been found 7\%. Chapman et al. [18] showed in a large study that combined hepatic arterial injury was demonstrated in $13.8 \%$ of patients with bile duct injury after open cholecystectomy. In a multi-institutional collective series of 77,704 laparoscopic cholecystectomies the incidence of right hepatic artery injury was $12 \%$ among patients with bile duct injury [19]. In series with bile duct injury, however, where routine angiography was performed, the incidence rises up to $39 \%$ in open [20] and $47 \%$ in laparoscopic cholecystectomy [15]. It seems, therefore, that despite the methodological problems mentioned, the incidence of concomitant vascular injury has been underestimated in the past. The most common vascular structure injured during dissection of Calot's triangle in laparoscopic cholecystectomy is by far the right hepatic artery; portal vein - usually in combination with proper hepatic artery injury - ranks second, but it is a rather rare injury [15]. The right hepatic artery can be clipped, sectioned or cauterized, usually being mistaken as cystic artery or due to a blind use of clips because of bleeding during dissection and suboptimal view. RHA pseudoaneurysm formation is an interesting complication and frequently causes gastrointestinal or intraperitoneal bleeding [21].

There are several classification systems of bile duct injuries; Bismuth classification [20] is probably the most popular, although it was originally proposed to describe strictures. Strasberg classification [4] is the most recent and detailed one and it is mainly based on Bismuth's classification adopted in the laparoscopic era, where the injuries occur in a somewhat different pattern compared to those encountered in open cholecystectomy. However, a simple and effective classification of laparoscopic bile duct injuries which incorporates concomitant vascular injury according to the mechanism of injury is the Stewart-Way classification [3].

\section{Presentation and Consequences}

Right hepatic artery injury can be recognized when it happens during laparoscopic cholecystectomy or after conversion to laparotomy for early primary repair of a suspected bile duct injury. More often, though, the injury must be suspected in any patient with bile duct injury referred to for delayed repair or redo of an unsuccessful primary repair. Duplex ultrasonography is unreliable [12] in assessing potential vascular injury under these circumstances, but either celiac angiography or a CT scan showing a nonenhanced right lobe of the liver or a CT vascular reconstruction can confirm the presence of such an injury [3]. Theoretically, magnetic resonance angiography may be preferable especially to invasive angiography [22]. Unfortunately, the literature lacks such information, as the vast majority of the published series which include patients managed during the past decades - rely invariably on classic angiographic images.

It has been proposed that the presence of vascular injury may result in several complications which are related to the disruption of blood supply of two regions: (a) the liver parenchyma, and (b) the extrahepatic biliary tree. With regard to the first, right lobe atrophy, necrosis and abscess formation have been sporadically reported [710]. Some of these complications have rarely led to the need for hepatectomy or even liver transplantation and in one small series have been associated with increased mortality [13]. Buell et al. [13] have reported 1 patient with combined biliary and vascular injury who needed liver transplantation, while another patient listed for orthotopic liver transplantation died from sepsis prior to transplantation. Similar experience with 1 patient has also been reported by Frilling et al. [23]. These patients, however, suffered either common hepatic artery injury or combined portal injury, which clearly represent more serious scenarios. Coexisting portal vein injuries are particularly devastating injuries as a normal portal circulation is prerequisite for recuperation of the dearterialized liver parenchyma [23]. Portal vein injuries have also been sporadically reported and Madariaga et al. [7] managed to successfully reconstruct an occluded portal vein during biliary reconstruction. In any case, such devastating and fatal complications associated with combined vascular and bile duct injuries are exceptionally rare and refer 
Table 1. Earlier reports on the consequences of concomitant vascular injury

\begin{tabular}{|c|c|c|c|c|}
\hline Authors & Patients $^{\mathrm{a}}$ & Mortality & Morbidity & Stricture \\
\hline Davidoff et al. [6] & $8 / 12$ & no & no & NA \\
\hline Madariaga et al. [7] & $5 / 14$ & no & $\begin{array}{l}\text { hepatic ischemia }(n=1) \\
\text { hepatic duct necrosis }(n=2)\end{array}$ & no \\
\hline Holbert et al. [8] & 2/NA & NA & hepatic infarction $(n=2)$ & NA \\
\hline Smith et al. [9] & $1 / \mathrm{NA}$ & NA & hepatic infarction $(\mathrm{n}=1)$ & NA \\
\hline Gupta et al. [10] & $4 / 13$ & no & liver abscess $(n=2)$ & $2 / 4$ \\
\hline Bachellier et al. [11] & $3^{*} / 15$ & no & no & no \\
\hline
\end{tabular}

* RHA reconstruction in 2 of the 3 cases.

${ }^{\text {a }}$ Number of patients with vascular injury/total number of patients with biliary reconstruction. $\mathrm{NA}=$ Not available.
Table 2. Recent reports on the impact of concomitant vascular injury on outcomes after biliary reconstruction for bile duct injury

\begin{tabular}{|c|c|c|c|c|}
\hline Authors & Patients $^{\mathrm{a}}$ & Mortality & Morbidity & Stricture \\
\hline Koffron et al. [12] & $11 / 18^{*}$ & NA & NA & NA \\
\hline Buell et al. [13] & $13 / 49(26 \%)$ & increased & & \\
\hline Bilge et al. [14] & $29 / 50(58 \%)$ & no difference & increased & no difference \\
\hline Alves et al. [15] & $26 / 55(47 \%)$ & no difference & no difference & no difference \\
\hline Schmidt et al. [16] & $11 / 46(24 \%)$ & no difference & increased & increased \\
\hline Stewart et al. [3] & $84 / 261(32 \%)$ & no difference & increased $^{* *}$ & no difference \\
\hline
\end{tabular}

* After failure of primary biliary reconstruction.

** No difference in centers with special interest in HPB surgery.

a Number of patients with vascular injury/total number patients with biliary reconstruction. $\mathrm{NA}=$ Not available. to scarce case reports rather than series of patients, so firm conclusions regarding their management are difficult to be drawn on that basis. As regards to the impact of concomitant vascular injury to the extrahepatic biliary tree, it has been reported that the presence of vascular injury is associated with increased intraoperative bleeding during repair, more difficult reconstruction, and, most importantly, high incidence of anastomotic stricture due to bile duct ischemia. All these complications have been described in the literature in case reports and small case series during the past decade [6-11].

Table 1 shows several series or case reports with right hepatic artery injury combined with bile duct injury after laparoscopic cholecystectomy, published during the past decade. In table 2 more recent, but, most importantly, larger series are included. Unfortunately, all but one are retrospective series with the scientific disadvantages these type of studies are characterized by; it is extremely difficult, however, to conduct large prospective controlled trials for this type of pathology, even in a multi- centric way. In the absence, therefore, of prospective randomized trials and meta-analyses, the best information that can be extracted from the available literature represents level of evidence C. When comparing these two tables it becomes clear that the problem nowadays is well recognized in several centers with major interest in HPB surgery. It is possible that the relatively higher incidence of vascular injuries in the recent series compared with previous reports is attributed to the highly selected group of patients with such injuries these tertiary referral centers receive.

When isolating the two probably most important studies, the one by Alves et al. [15], because it is the only prospective study, and the one by Stewart et al. [3], because it is the largest, it appears that the results are very similar. Neither of the two studies showed any difference in mortality and anastomotic stricture incidence between patients who had isolated bile duct injury and those who had combined vascular and biliary injury. Overall morbidity did not differ between isolated or combined inju- 
ries, unless the repair was performed by the primary surgeon as opposed to a biliary specialist [3].

Alves et al. [15] proposed a Hepp-Couinaud reconstruction using the extrahepatic portion of the left hepatic duct in order to ensure adequate blood supply to the hepatico-jejunostomy and, thus, avoiding future development of anastomotic stricture. They have applied this type of reconstruction for Bismuth types I, II, III and IV injuries with satisfactory long-term results [15]. The communication between the left and right hepatic arteries via the hilar plate arterial plexus develops very rapidly after the right hepatic artery injury and provides adequate arterial blood supply to both the right hepatic lobe and the biliary tree proximal to the confluence $[24,25]$. Furthermore, by using this type of reconstruction, the size of the anastomosis is larger as the left hepatic duct is opened longitudinally to be anastomosed to the jejunal loop, and therefore less prone to stenosis. Although the HeppCouinaud reconstruction appears to offer some advantages, it has never been tested in a comparative trial; on the other hand, it cannot be used in all injuries. Bismuth type $\mathrm{V}$ injuries would require separate duct anastomoses $[26,27]$ and sometimes hepatic resection [28]. Lillemoe et al. [26] have described a technique similar to that used for a left-sided approach, by resecting the base of the gallbladder fossa, exposing the right ducts to allow separate anastomoses to be fashioned. Regardless of the potential superiority of one technique over the other, however, the most important prognostic factor of morbidity and longterm functional outcome after biliary reconstruction is probably the surgeon. There is little doubt that the best results for this type of surgery have been achieved in high-volume tertiary referral centers and/or surgeons with HBP interest [3].

\section{What Do We Do when Faced with This Type of}

Injury?

In case this happens at the time of cholecystectomy and becomes promptly apparent, one could try to repair the vascular injury if possible, according to some authors $[10,11]$. Others suggest arterial reconstruction when the distal right hepatic artery can be exposed even for the delayed biliary reconstruction and this has been sporadically performed with satisfactory results $[7,11]$. Timing is probably a crucial issue, not for the arterial injury per se but for the concomitant biliary injury, although this has been a matter of debate. There have been reports with contradictory results $[28,29]$, but the impact of surgeon's experience should be taken into account when analyzing the results. Although good results have been reported with early biliary repair by an HBP surgeon, it seems prudent to delay the repair in case of disruption of the confluence or when significant thermal injury or surrounding sepsis is present [22]. The delay in these cases will allow the final level of injury to demarcate, determine the need for hepatic resection and also allow the ducts to dilate and mature to improve the likelihood of a successful repair $[27,29]$. With regard to the arterial injury, many authors have recently suggested to ignore it regardless of the timing of recognition and/or repair, as the consequences of right hepatic artery ligation in an otherwise healthy liver have been unremarkable and recommendations are generally not to attempt to reconstruct the injured artery $[3,17]$. Experimental studies have also suggested that the incidence of hepatic lobe necrosis after right hepatic artery ligation is insignificant in the absence of concurrent cholestasis [30, 31].

In conclusion, vascular injuries during laparoscopic cholecystectomy are encountered almost exclusively in the context of bile duct injury; they occur more often than believed in the past and tend to be located more proximal compared to those observed in open surgery. There is no evidence they increase mortality, but they may cause increased morbidity and jeopardize the longterm functional results of biliary reconstruction by causing anastomotic strictures. When identified early, there is some space for repair, although this is controversial; in delayed cases it seems reasonable to ignore the vascular injury per se. A Hepp-Couinaud reconstruction is proposed to overcome the problem of future biliary stricture formation due to ischemia, but most importantly, a reconstruction performed in a HBP center or by an HBP surgeon is of paramount importance in order to ensure the best long-term functional results. 


\section{References}

1 Shamiyeh A, Wayand W: Laparoscopic cholecystectomy: early and late complications and their treatment. Langenbecks Arch Surg 2004;389:164-171.

-2 Schafer M, Lauper M, Krahenbuhl L: A nation's experience of bleeding complications during laparoscopy. Am J Surg 2000;180:7377.

-3 Stewart L, Robinson TN, Lee CM, Lin K, Whang K, Way L: Right hepatic injury associated with laparoscopic bile duct injury: Incidence, mechanism and consequences. J Gastrointest Surg 2004;8:523-531.

4 Strasberg SM, Hertl M, Soper NJ: An analysis of the problem of biliary injury during laparoscopic cholecystectomy. J Am Coll Surg 1995;189:101-125.

5 Fletcher DR, Hobbs MST, Tan P, Valinsky LJ, Hockey RL, Pikora TJ, et al: Complications of cholecystectomy: risks of the laparosocpic approach and protective effects of operative cholangiography: a population based study. Ann Surg 1999;229:449-457.

6 Davidoff AM, Pappas TN, Murray EA, Hilleren DJ, Johnson RD, Baker ME, Newman GE, Connon PB, Meyers WC: Mechanisms of major biliary injury during laparoscopic cholecystectomy Ann Surg 1992;215:196202.

$>7$ Madariaga JR, Dodson SF, Selby R, Todo S, Iwatsuki S, Starzl TE: Corrective treatment and anatomic considerations for laparoscopic cholecystectomy injuries. J Am Coll Surg 1994;179:321-325.

$\checkmark 8$ Holbert BL, Baron RL, Dodd GD 3rd: Hepatic infarction caused by arterial insufficiency: spectrum and evolution of CT findings. Am J Gastroenterol 1996;166:815.

$\checkmark 9$ Smith GS, Birnbaum BA, Jacobs JE: Hepatic infarction secondary to arterial insufficiency in native livers: CT findings in 10 patients. Radiology 1998;208:223-229.

-10 Gupta N, Solomon H, Fairchild R, Kaminski $\mathrm{D}$ : Management and outcome of patients with combined bile duct and hepatic artery injuries. Arch Surg 1998;133:176-181.
11 Bachellier P, Nakano H, Weber JC, Lemarque P, Oussoultzoglou E, Candau C, Wolf P, Jaeck D: Surgical repair after bile duct and vascular injuries during laparoscopic cholecystectomy: when and how? World J Surg 2001;25:1335-1345.

12 Koffron A, Ferrario M, Parsons W, Nemcek A, Saker M, Abecassis M: Failed primary management of iatrogenic biliary injury: incidence and significance of concomitant hepatic arterial disruption. Surgery 2001;130: 722-731.

13 Buell JF, Cronin DC, Funaki B, Koffron A, Yoshida A, Lo A, et al: Devastating and fatal complications associated with combined vascular and bile duct injuries. Arch Surg 2002;137:703-710

14 Bilge O, Bozkiran S, Ozden I, Tekant Y, Acar li K, Alper A, Emre A, Ariogul O: The effect of concomitant vascular disruption in patients with iatrogenic biliary injuries. Langenbecks Arch Surg 2003;388:265-269.

15 Alves A, Farges O, Nicolet J, Watrin T, Sauvanet $\mathrm{A}$, Belghiti $\mathrm{J}$ : Incidence and consequence of an hepatic artery injury in patients with postcholecystectomy bile duct strictures. Ann Surg 2003;238:93-96.

16 Schmidt SC, Settmacher U, Langrehr JM, Neuhaus P: Management and outcome of patients with combined bile duct and hepatic arterial injuries after laparoscopic cholecystectomy. Surgery 2004;135:613-618.

17 Halasz NA: Cholecystectomy and hepatic artery injury. Arch Surg 1991;126:137-138.

18 Chapman WC, Halevy A, Blumgart LH, Benjamin IS: Post-cholecystectomy bile duct strictures: management and outcome in 130 patients. Arch Surg 1995;130:597-604.

19 Deziel DJ, Millikan KW, Economou SG Doolas A, Ko ST, Airan MC: Complications of laparoscopic chomesystectomy: a national survey of 4,292 hospials and an analysis of 77,704 cases. Am J Surg 1993;165:9-14.

20 Bismuth $\mathrm{H}$ : How to treat a postoperative stenosis?; in Bismuth $\mathrm{H}$, Lazorthes F (eds): Operative Injury of the Common Bile Duct. Paris, Masson, 1981, pp 47-107.

21 Nicholson T, Travis S, Ettles D, Dyet J, Sedman P, Wedgewood K, Royston C: Hepatic artery angiography and embolization for hemobilia following laparoscopic cholecystectomy. Cardiovasc Intervent Radiol 1999;22: 20
22 Connor S, Garden OJ: Bile duct injury in the era of laparoscopic cholecystectomy. Br J Surg 2006;93:158-168.

23 Frilling A, Li J, Weber F, Frubauf NR, Engel J, Beckebaum S, Paul A, Zopf T, Malago M, Broelsch CE: Major bile duct injuries after laparoscopic cholecystectomy: a tertiary center experience. J Gastrointest Surg 2004; 8:679-685

24 Mays ET, Wheeler CS: Demonstration of collateral arterial flow after interruption of hepatic arteries in man. N Engl J Med 1974;290: 993-996.

25 Vellar ID: The blood supply of the biliary ductal system and its relevance to vasculobiliary injuries following cholecystectomy. Aust N Z J Surg 1999;69:816-820.

26 Lillemoe KD, Martin SA, Cameron JL, Yeo CJ, Talamani MA, Kaushal S, et al: Major bile duct injuries during laparoscopic cholecystectomy: follow-up after combined surgical and radiologic management. Ann Surg 1997; 225:459-471.

27 Strasberg SM, Picus DD, Drebin JA: Results of a new strategy for reconstruction of biliary injuries having an isolated right-sided component. J Gastrointest Surg 2001;5:266-274.

28 Thomson BNJ, Parks RW, Madhavan KK, Wigmore SJ,Garden OJ: Early repair of biliary injury. Br J Surg 2006;93:216-220.

29 Chaudhary A, Chandra A, Negi SS, Sachdev A: Reoperative surgery for postcholecystectomy bile duct injuries. Dig Surg 2002;19: 753-757.

30 Okada Y: Experimental study on the interruption of hepatic blood flow in obstructive jaundice, with special reference to the causes of death and prolonged jaundice after biliary decompression. Nippon Geka Hokan 1989; 58:275-288.

31 Soares AF, Castro e Silva Junior O, Cenevina R, Roselino JE, Zucoloto S: Biochemical and morphological changes in the liver alter hepatic artery ligation in the presence or absence of extrahepatic cholestasis. Int J Exp Pathol 1993;74:367-370. 